LIVER DISEASE

\title{
Thrombotic risk factors and extent of liver fibrosis in chronic viral hepatitis
}

\author{
G V Papatheodoridis, E Papakonstantinou, E Andrioti, E Cholongitas, K Petraki, \\ I Kontopoulou, S J Hadziyannis
}

\begin{abstract}
Background and aims: Thrombosis of the small intrahepatic veins has been suggested to trigger liver tissue remodelling. We evaluated the prevalence of multiple thrombotic risk factors and their association with the extent of fibrosis in chronic viral hepatitis.

Methods: Ninety consecutive patients with chronic hepatitis B or C without malignancy, a history of venous thrombosis, or antiviral/immunosuppressive therapy within the last six months were included. Thrombophilic and coagulation factors were evaluated on the liver biopsy day.

Results: One or more thrombotic risk factors were found in $68 \%$ and $\geqslant 2$ factors in $37 \%$ of patients. Higher necroinflammatory activity was independently associated with higher prothrombin time $(p=0.003)$, alanine aminotransferase level $(p=0.011)$, and histological staging $(p=0.018)$. Patients with staging scores of 4-6 compared with those with scores of 0-3 more frequently had deficiency of protein C (24\% v $3 \%$; $p=0.007)$, antithrombin III (28\% v 5\%; $p=0.005)$, and plasminogen $(19 \%$ v $2 \%$; $p=0.03)$, and a trend for more frequent activated protein $C$ resistance $(8 \% v 0 \% ; p=0.075)$. The presence of $\geqslant 1$ significant thrombotic risk factor was observed in $11 / 25(44 \%)$ patients with staging scores of $4-6$ and in $6 / 65(9 \%)$ patients with scores of $0-3(p<0.001)$, being the only variable independently associated with advanced staging (odds ratio $2.4, p=0.02$ )

Conclusions: Thrombotic risk factors are frequently detected in patients with chronic viral hepatitis and the presence of $\geqslant 1$ significant factor is associated with more advanced fibrosis. Whether the association of such thrombophilic conditions with advanced fibrosis is a primary or secondary phenomenon and whether their development in combination with local inflammation accelerate the progression of liver fibrosis need further evaluation.
\end{abstract}

$\begin{aligned} & \text { See end of article for } \\ & \text { authors' affiliations }\end{aligned}$
$\ldots \ldots \ldots \ldots \ldots \ldots \ldots \ldots$
Correspondence to:
S J Hadziyannis,
Department of Medicine
and Hepatology, Henry
Dunant Hospital, 107
Mesoghion Ave, Athens,
Greece;
hadziyannis@ath.forthnet.gr
Accepted for publication
9 October 2002

See end of article for October 2002

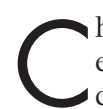
hronic viral hepatitis can be a progressive disease. It is estimated that approximately $20-30 \%$ of patients with chronic hepatitis $C$ progress to cirrhosis over a period of 20 years $^{12}$ and about $15-20 \%$ of patients with chronic hepatitis B may do so within five years. ${ }^{3}{ }^{4}$ Patients with established cirrhosis have a poor prognosis as they are at high risk of liver decompensation and/or the development of hepatocellular carcinoma (HCC).$^{5-8}$ In chronic viral hepatitis, cirrhosis is considered to be the end result of a diffuse chronic necroinflammatory process and is characterised by extensive fibrosis and abnormal hepatic architecture with nodule formation. ${ }^{9}$ All recent histological classification systems of chronic viral hepatitis have separated necroinflammatory activity (referred to as grading) from fibrosis (often referred to as staging).$^{10-12}$

Hepatic fibrosis develops as a response to chronic liver damage from several causes but acute severe or even fulminant hepatitis often resolves without the development of fibrosis, ${ }^{13}$ which suggests that liver necroinflammation may not be sufficient to initiate production of permanent fibrosis. Although there have been many studies attempting to evaluate the rate of progression to cirrhosis and several factors have been associated with rapid or slow progression of fibrosis, ${ }^{1-4}$ it is very difficult to predict the course of the disease in individual patients. Thrombosis of the intrahepatic veins is frequently observed in cirrhosis and has been associated with its progression, ${ }^{14}$ while occlusion of small sized intrahepatic veins and sinusoids has been considered as a potential triggering factor of liver tissue remodelling. ${ }^{15}$ The involvement of various thrombotic risk factors in the pathogenesis of vein thrombosis is well established but their role in chronic viral hepatitis or cirrhosis has not been investigated. In the present study, we evaluated the prevalence of several genetic and acquired prothrombotic conditions in patients with chronic hepatitis B or C as well as their possible association with necroinflammatory activity (grading) and extent of fibrosis (staging) of liver disease.

\section{PATIENTS AND METHODS \\ Patient population}

Ninety consecutive patients with chronic hepatitis B or C admitted to our department for a liver biopsy between March 2000 and February 2001 were included in this study. Patients with known HCC or any other malignancy, a history of venous thrombosis, or those who had received any form of antiviral and/or immunomodulatory therapy within the last six months were excluded. No patient was taking oral contraceptives or anticoagulation therapy.

\section{Liver histology}

All 90 patients had a percutaneous liver biopsy. There were no inadequate liver specimens, as defined previously on the basis of no portal tracts identified or the specimen size itself being too small to make a diagnosis. All liver biopsies were evaluated blindly by a single liver histopathologist (KP) and histological changes of chronic hepatitis were classified according to the classification system proposed by Ishak and colleagues. ${ }^{11}$ The chronic hepatitis grading score $(0-18)$, which represents necroinflammatory activity, was the sum of the piecemeal necrosis score (0-4), confluent necrosis score (0-6), focal lytic necrosis, apoptosis, and focal inflammation score (0-4), and

Abbreviations: HCC, hepatocellular carcinoma; ALT, alanine aminotransferase; AST, aspartate aminotransferase; GGT, gamma-glutamyl-transpeptidase; ULN, upper limit of normal 
Table 2 Levels of thrombophilic and coagulation factors in 90 patients with chronic hepatitis B or C

\begin{tabular}{|c|c|c|c|c|}
\hline Factor & Chronic hepatitis B & Chronic hepatitis C & Total & Normal range \\
\hline $\lg \mathrm{G}$ aCL antibodies (U/ml) & $5.7(1.7)(1.6-10.1)^{*}$ & $4.9(1.8)(1.1-10.1)^{*}$ & $5.2(1.8)(1.1-10.1)$ & $<10$ \\
\hline IgM aCL antibodies (U/ml) & $7.3(5.4)(1.4-23.4)^{* *}$ & $5.3(2.1)(1.0-11.5)^{* *}$ & $6.2(4.0)(1.4-23.4)$ & $<10$ \\
\hline Protein C levels (\%) & 95 (26) (50-166) & 102 (24) (46-163) & $99 \quad(25)(46-166)$ & $70-140$ \\
\hline Protein S levels (\%) & 84 (25) (46-150) & (25) $(30-130)$ & (25) (30-150) & $65-140$ \\
\hline Antithrombin III levels (\%) & 95 (17) $(45-121)^{* * *}$ & (14) $(53-136)^{* * *}$ & (17) (45-136) & $80-140$ \\
\hline Plasminogen levels (mg/dl) & 91 (13) $(63-116)^{* * * *}$ & $98(15)(65-134)^{* * * *}$ & (15) (63-134) & $75-140$ \\
\hline APC ratio & $2.8(0.4)(2.1-3.8)$ & $2.7(0.4)(2.1-3.6)$ & $2.8(0.4)(2.1-3.8)$ & $>2.2$ \\
\hline Factor VIII levels (\%) & $168 \quad$ (67) (71-390) & $165 \quad(64)(68-391)$ & $166 \quad(65)(68-391)$ & $60-150$ \\
\hline Factor IX levels (\%) & (32) (59-173) & (43) (49-200) & (39) (49-200) & $>60$ \\
\hline Factor XI levels (\%) & (29) $(50-171)$ & (43) (29-200) & (38) (29-200) & $>60$ \\
\hline Factor XII levels (\%) & (37) (23-200) & (36) (43-200) & (36) (23-200) & $>60$ \\
\hline
\end{tabular}

Quantitative values are expressed as mean (SD) (range).

$\mathrm{aCL}$, anticardiolipin; APC, activated protein C.

Chronic hepatitis B versus chronic hepatitis C patients: ${ }^{*} \mathrm{p}=0.04 ;{ }^{*} \mathrm{p}=0.02 ;{ }^{* *} \mathrm{p} p<0.001 ;{ }^{* * *} \mathrm{p}=0.01$.

\begin{tabular}{|c|c|c|c|}
\hline \multicolumn{4}{|l|}{$\begin{array}{l}\text { Table } 3 \\
\text { or C }\end{array}$} \\
\hline Thrombotic risk factor & $\begin{array}{l}\text { Chronic hepatitis } \\
\text { B (n (\%)) }\end{array}$ & $\begin{array}{l}\text { Chronic hepatitis C } \\
\text { (n (\%)) }\end{array}$ & $\begin{array}{l}\text { Total } \\
\text { (n (\%)) }\end{array}$ \\
\hline $\begin{array}{c}\mathrm{aCL} \text { antibodies elevated } \\
(\mathrm{lg} / \mathrm{lg} M / \lg G+\lg M)\end{array}$ & $\begin{array}{l}4(10.2) \\
(0 / 3 / 1)\end{array}$ & 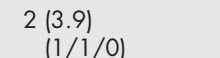 & 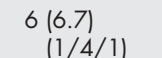 \\
\hline Protein $C$ deficiency & $5(12.8)$ & $3(5.9)$ & $8(8.9)$ \\
\hline Protein S deficiency & $8(20.5)$ & 19 (37.3) & 27 (30.0) \\
\hline Antithrombin III deficiency & $9(23.1)$ * & $1(2.0)^{*}$ & $10(11.1)$ \\
\hline Plasminogen deficiency & $2(5.1)$ & $3(5.9)$ & $5(5.6)$ \\
\hline $\mathrm{APC}$ resistance $\dagger$ & $1(2.6)$ & $1(2.0)$ & $2(2.2)$ \\
\hline Prothrombin $20210 \mathrm{~A}$ mutation $\neq$ & $4(10.2)$ & $2(3.9)$ & $6(6.7)$ \\
\hline Factor VIII levels elevated & $23(59.0)$ & $28(54.9)$ & $51(56.7)$ \\
\hline$\geqslant 1$ thrombotic risk factor & $25(64.1)$ & $36(70.6)$ & $61(67.8)$ \\
\hline$\geqslant 2$ thrombotic risk factors & $16(41.0)$ & 17 (33.3) & $33(36.7)$ \\
\hline \multicolumn{4}{|c|}{$\begin{array}{l}\text { aCL, anti-cardiolipin; } A P C \text {, activated protein } C \text {. } \\
+ \text { None of the two cases with } A P C \text { resistance was found to have the factor } V \text { Leiden mutation. } \\
\text { †All six patients were heterozygous for the prothrombin } 20210 A \text { mutation. } \\
\text { Chronic hepatitis B versus chronic hepatitis } C \text { patients: }{ }^{*} p=0.005 \text {. }\end{array}$} \\
\hline
\end{tabular}

hepatitis B and C cases, except for antithrombin III deficiency that was detected significantly more frequently in chronic hepatitis B than C patients $(23 \% \vee 2 \% ; \mathrm{p}=0.005)$. Elevated factor VIII levels and protein $S$ deficiency were the most common thrombotic factors detected in $57 \%$ and $30 \%$ of cases, respectively. In particular, protein $\mathrm{S}$ deficiency was found relatively more frequently in chronic hepatitis $\mathrm{C}$ than B patients ( $37 \%$ v $21 \% ; \mathrm{p}=0.14)$ while elevated anticardiolipin antibodies and the prothrombin 20210A mutation (only heterozygous cases) were detected in $10 \%$ and $4 \%(p=0.44)$ and protein $\mathrm{C}$ deficiency in $13 \%$ and $6 \%$ of chronic hepatitis $\mathrm{B}$ and $\mathrm{C}$ patients, respectively $(p=0.44)$. Activated protein $C$ resistance and plasminogen deficiency were detected in less than $3 \%$ and $6 \%$ of cases. No patient had the factor V Leiden mutation. At least one thrombotic risk factor was present in $68 \%$ and two or more thrombotic risk factors in $37 \%$ of our patients (table 3 ). Moreover, one or more coagulation factor deficiencies $(<60 \%)$ were found in $16 \%$ of 90 patients without any significant difference between chronic hepatitis B and C cases ( $7 / 39$ or $17.9 \%$ $v 7 / 51$ or $13.7 \%$, respectively; $\mathrm{p}=0.80$ ).

Higher necroinflammatory activity (histological grading as a continuous variable) was found to be significantly associated with older age $(p=0.006)$, lower platelet count $(p=0.02)$, more prolonged prothrombin time $(p<0.001)$, higher ALT levels $(\mathrm{p}=0.007)$, higher AST levels $(\mathrm{p}<0.001)$, higher histological staging $(p<0.001)$, protein $C$ deficiency $(p=0.04)$, and antithrombin III deficiency $(p=0.02)$, while there was a trend towards an association with lower fibrinogen levels $(p=0.07)$ and plasminogen deficiency $(\mathrm{p}=0.09)$. Multivariate analysis showed that higher necroinflammatory activity was independently associated only with more prolonged prothrombin time $(p=0.003)$, higher ALT levels $(p=0.011)$, and higher histological staging $(\mathrm{p}=0.018)$.

Higher histological staging (as a continuous variable) was also significantly associated with older age $(p<0.001)$, lower white blood cell count $(\mathrm{p}=0.024)$, lower platelet count $(\mathrm{p}<0.001)$, more prolonged prothrombin time $(\mathrm{p}<0.001)$, higher AST levels $(p=0.02)$, higher GGT levels $(p=0.01)$, higher histological grading $(\mathrm{p}<0.001)$, protein $\mathrm{C}$ deficiency $(\mathrm{p}<0.001)$, protein $\mathrm{S}$ deficiency $(\mathrm{p}=0.04)$, antithrombin III deficiency $(p<0.001)$, elevated factor VIII levels $(p=0.047)$, and plasminogen deficiency $(\mathrm{p}<0.001)$, and relatively associated with activated protein $C$ resistance $(p=0.06)$. Multivariate analysis showed that higher staging was independently associated only with higher GGT levels $(p=0.013)$ and antithrombin III deficiency $(\mathrm{p}=0.01)$.

Associations of histological staging scores 4-6 (advanced) or scores $0-3$ with patient characteristics and with levels of thrombophilic and coagulation factors and the presence of thrombotic risk factors are presented in tables 4 and 5, respectively. Patients with compared with those without advanced staging were significantly older ( $52 v 42$ years; $p=0.001$ ), had a lower platelet count $\left(170 \vee 222 \times 10^{3} / \mathrm{l} ; \mathrm{p}=0.001\right)$, more prolonged prothrombin time $(12.2 \vee 11.7 \mathrm{~s} ; \mathrm{p}=0.02)$, higher AST levels (69 $v 47$ IU/l; $\mathrm{p}=0.005)$, higher alkaline phosphatase levels (0.7 $v$ 0.6xupper limit of normal (ULN); $\mathrm{p}=0.023)$, higher GGT levels $(0.9 v 0.5 \times \mathrm{ULN} ; \mathrm{p}=0.017)$, and higher grading ( $8.1 \vee 6.5 ; \mathrm{p}=0.002)$ (table 4$)$. In addition, patients with advanced staging also had significantly more frequently protein C deficiency $(24 \% \vee 3 \%$; $=0.007)$, antithrombin III deficiency $(28 \% \vee 5 \%$; $=0.005)$, and plasminogen deficiency $(19 \% \vee 2 \% ; p=0.03)$, and relatively 
Table 4 Epidemiological, haematological, biochemical, and histological characteristics of 90 patients with chronic hepatitis B or $C$ in relation to their histological staging

\begin{tabular}{|c|c|c|c|}
\hline Characteristic & Staging $0-3(n=65)$ & Staging 4-6 $(n=25)$ & $\mathrm{p}$ Value \\
\hline $\operatorname{Sex}(M / F)$ & $47 / 18$ & $17 / 8$ & 0.89 \\
\hline Age $(y)$ & 42 & (14) & 0.001 \\
\hline Possible source of infection (n) & & & 0.60 \\
\hline Blood transfusion & 15 & 4 & \\
\hline Parenteral drug use & 10 & 5 & \\
\hline Intrafamilial contact & 14 & 5 & \\
\hline Health care work & 0 & 1 & \\
\hline Unknown & 26 & 10 & \\
\hline Haemoglobin (g/dl) & $14.1(1.5)$ & $14.0(1.4)$ & 0.74 \\
\hline White blood cell count $\left(\times 10^{3} / 1\right)$ & $7.3(2.1)$ & 6.5 (1.9) & 0.11 \\
\hline Platelet count $\left(\times 10^{3} / \mathrm{I}\right)$ & 222 (59) & $170 \quad(63)$ & 0.001 \\
\hline Prothrombin time $(\mathrm{s})$ & $11.7(0.8)$ & $12.2(1.0)$ & 0.02 \\
\hline Partial thromboplastin time (s) & 32 (4) & $30 \quad(5)$ & 0.16 \\
\hline Fibrinogen levels (mg/dl) & 264 & $266 \quad(56)$ & 0.88 \\
\hline ALT (IU/I) & $(24-490)$ & 115 (25-230) & 0.07 \\
\hline AST (IU/I) & $47 \quad(19-213)$ & 69 (33-179) & 0.005 \\
\hline Alkaline phosphatase (xULN) & $0.6(0.3-1.4)$ & $0.7(0.3-1.2)$ & 0.023 \\
\hline GGT $(x$ ULN) & $0.5(0.2-2.9)$ & $0.9(0.2-3.0)$ & 0.017 \\
\hline Histological grading & $6.5(2.2)$ & $8.1(2.3)$ & 0.002 \\
\hline Piecemeal necrosis score & $1.8(0.8)$ & $2.4(0.8)$ & 0.004 \\
\hline Confluent necrosis score & $0.4(0.7)$ & $0.7(0.8)$ & 0.04 \\
\hline Focal inflammation score* & $1.9(0.6)$ & $2.1(0.6)$ & 0.16 \\
\hline Portal inflammation score & $2.4(0.7)$ & $3.0(0.7)$ & 0.001 \\
\hline \multicolumn{4}{|c|}{$\begin{array}{l}\text { Quantitative values are expressed as mean (SD) or median (range). } \\
\text { *Focal lytic necrosis, apoptosis, and focal inflammation score. } \\
\text { ALT, alanine aminotransferase; AST, aspartate aminotransferase; GGT, gamma-glutamyl- transpeptidase; } \\
\text { ULN, upper limit of normal. }\end{array}$} \\
\hline
\end{tabular}

more frequently activated protein $\mathrm{C}$ resistance $(8 \% \vee 0 \%$; $\mathrm{p}=0.075$ ). Elevated anticardiolipin antibody levels, prothrombin 20210A mutation, protein S deficiency, and elevated factor VIII levels were not found to be associated with advanced staging. Two or more thrombotic risk factors were present in $56 \%$ of patients with advanced staging and in only $29 \%$ of those with staging $1-3$ (odds ratio $3.1,95 \%$ confidence interval $1.2-8.0 ; p=0.03$ ), while deficiency of one or more coagulation factors was not associated with staging (table 5).

One or more significant thrombotic risk factors (antithrombin III deficiency, protein C deficiency, plasminogen deficiency, activated protein $\mathrm{C}$ resistance) were present in 11 (44\%) of 25 patients with staging $4-6$ and in only $6(9 \%)$ of 65 patients with staging $0-3(\mathrm{p}<0.001)$. Logistic regression analysis showed that the presence of at least one significant thrombotic risk factor was the only variable independently associated with advanced staging (adjusted odds ratio 2.4, 95\% confidence interval 1.14-5.0; $\mathrm{p}=0.02$ ).

\section{DISCUSSION}

Our study has evaluated for the first time the association between thrombotic risk factors, detected by comprehensive thrombophilic screening, and severity of necroinflammatory activity or fibrosis in patients with chronic viral hepatitis. At least one thrombotic risk factor was detected in $68 \%$ and two or more factors in $37 \%$ of patients with chronic hepatitis B or C. As protein C, protein S, antithrombin III, and plasminogen are produced by the liver, their levels may decrease in patients with chronic liver disease. ${ }^{16}$ This is usually considered to be the case in established cirrhosis where such anticoagulant factors decrease in parallel with reductions in the levels of coagulation factors. ${ }^{16}$ However, deficiency of coagulation factor VIII, IX, XI, or XII was found in only $16 \%$ of our patients and thus impairment of hepatocellular production cannot be exclusively to blame for the observed high prevalence of protein $\mathrm{C}$, protein $\mathrm{S}$, antithrombin III, and plasminogen deficiency. It should also be noted that patients with clinical signs of cirrhosis were excluded from our study and that only
$13 \%$ of the patients included had a fibrosis score of 5 or 6 , corresponding to the cirrhotic stage.

Thrombotic risk factors were found to be independently associated with the extent of fibrosis but not with the degree of necroinflammatory activity. In particular, antithrombin III deficiency was independently associated with more extensive fibrosis, and the presence of at least one of four significant thrombotic risk factors (antithrombin III, protein C, plasminogen deficiency, and activated protein $\mathrm{C}$ resistance) was the only variable associated with advanced staging of chronic hepatitis. The observed association between thrombotic risk factors and advanced staging supports the hypothesis of vascular obstruction for the histological progression of chronic viral hepatitis. ${ }^{14}{ }^{15}$ Obliteration of small portal and hepatic veins due to thrombosis and phlebitis has been proposed as an important factor for the progression of chronic liver disease as it results in local hepatocyte death and the development of fibrosis (parenchymal extinction). ${ }^{14}{ }^{15}$ In fact, in cirrhotic livers, obstruction of small intrahepatic portal and hepatic veins is observed almost invariably. ${ }^{17}{ }^{18}$ Thus changes in the composition of the blood towards a hypercoagulable state in combination with changes in the endothelium of intrahepatic vessels and/or in intrahepatic blood flow, which often develop in chronic liver disease with fibrosis, ${ }^{19} 20$ certainly favour the development of thrombosis in intrahepatic veins. Thus one could hypothesise that patients with chronic viral hepatitis who carry specific genetic or develop more easily specific acquired thrombotic risk factors have a more rapid progression to more severe staging of chronic hepatitis. Alternatively, the higher prevalence of some thrombotic risk factors in patients with more severe staging may reflect greater impairment of anticoagulant production by patients with more advanced liver disease. Even if this is the case, however, the secondary development of anticoagulant deficiency favours the development of intrahepatic vein thrombosis and further parenchymal extinction.

Elevated levels of factor VIII and protein S deficiency were the two thrombotic risk factors that were most frequently detected in our population but none was found to be 
Table 5 Levels of thrombophilic and coagulation factors or presence of thrombotic risk factors in 90 patients with chronic hepatitis B or $C$ in relation to their histological staging

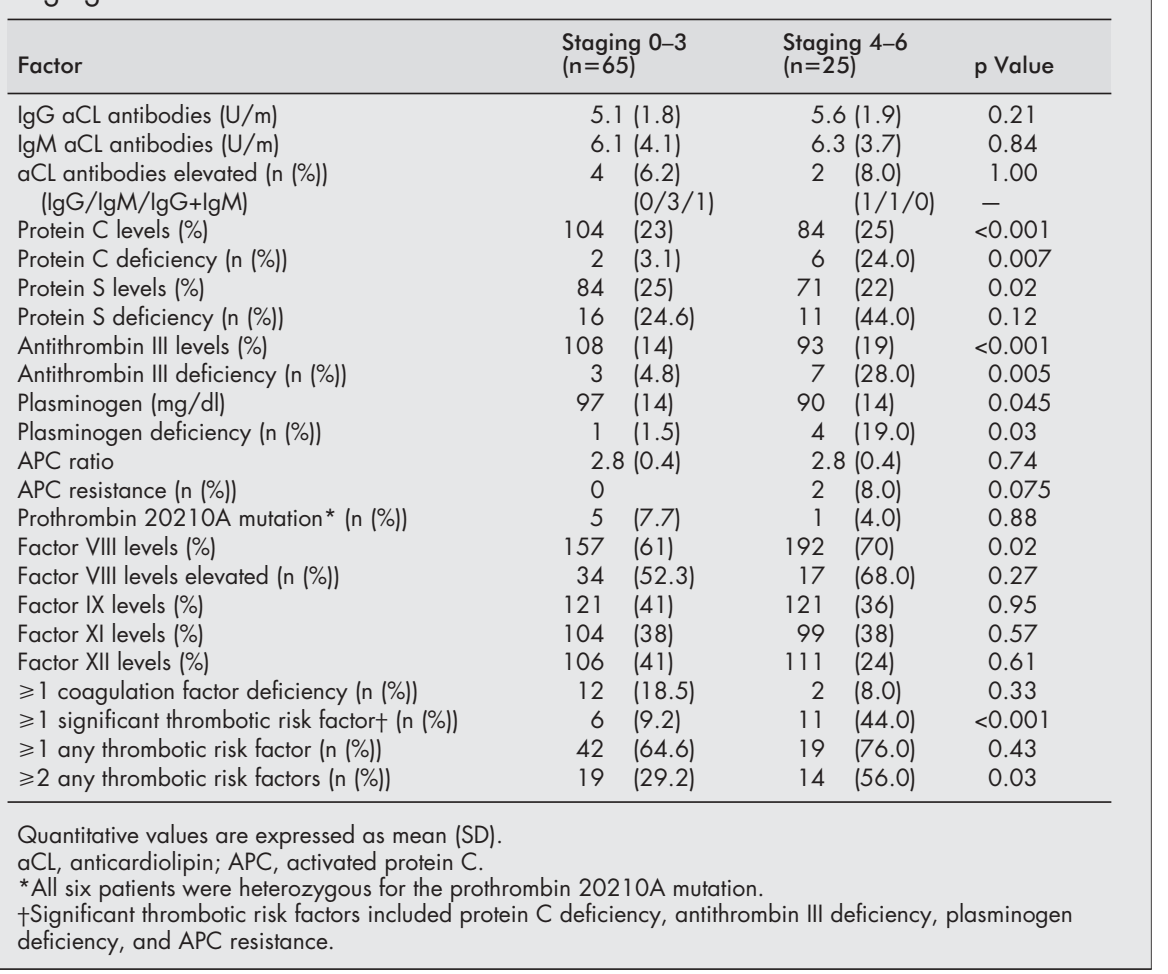

associated with staging of disease. Levels of factor VIII and Willebrand's factor are known to increase in chronic liver disease but this is usually due to a disproportionate increase in procoagulant antigens compared with functional coagulant active proteins of these two factors. ${ }^{1621}$ Of protein $S$ plasma concentrations, $60 \%$ are bound to a complement binding protein, which increases in inflammatory conditions, and only $40 \%$ represent the active free form of protein S, which is a cofactor of activated protein $\mathrm{C}$ and not a direct anticoagulant. ${ }^{1622}$ Thus laboratory findings of elevated levels of factor VIII or protein $\mathrm{S}$ deficiency may not always reflect abnormal anticoagulant activity.

Antithrombin III, protein C, and plasminogen deficiency were the thrombotic risk factors that were found to be significantly associated with advanced staging while there was a trend towards an association with activated protein C resistance. In particular, antithrombin III or protein C deficiency as well as activated protein $\mathrm{C}$ resistance are considered to be strong thrombotic factors increasing the risk by approximately $8-10$-fold. ${ }^{23}$ In contrast, the presence of the prothrombin 20210A mutation, which was not associated with severity of fibrosis in our study, is generally considered to be a mild thrombotic risk factor increasing the risk by only $2-3$-fold. ${ }^{23}$ Finally, the presence of two or more of any of the thrombotic risk factors, which represents a condition with an increased risk of thrombosis, ${ }^{23}$ was also significantly associated with advanced staging.

Increased levels of anticardiolipin but with no anti-beta2glycoprotein I antibodies, which are usually needed for the development of thrombosis associated with positive anticardiolipin antibodies, or the presence of lupus anticoagulant, were not associated with histological staging in our study. Anticardiolipin antibodies have been reported to be present in up to $44 \%$ of patients with hepatitis $\mathrm{C}$ virus infection but their clinical significance remains controversial. ${ }^{24}$ In chronic hepatitis C, such antibodies have sometimes been associated with the development of thrombocytopenia, portal hypertension, or thrombotic events. ${ }^{24-26}$ Positive anticardiolipin antibodies were detected in only $4 \%$ and $10 \%$ of our chronic hepatitis C and B patients, respectively. None of our six patients with positive anticardiolipin antibodies had a history of thrombotic episodes or clinical signs of portal hypertension, only two had advanced histological staging, and only one had a relatively low platelet count $\left(120 \times 10^{3} / 1\right)$. Thus our data are in agreement with reports suggesting that anticardiolipin antibodies are positive in less than $5 \%$ of chronic hepatitis $C$ patients and seem to represent an epiphenomenon without any clinical relevance. ${ }^{24} 27$

The prevalence of thrombotic risk factors or of coagulation factor deficiency evaluated in this study did not significantly differ between chronic hepatitis B and C patients, except for antithrombin III deficiency which was observed in $23 \%$ and $2 \%$ in the two groups, respectively. This isolated difference may represent a specific effect of chronic hepatitis B virus infection or may be associated with more severe liver disease in chronic hepatitis B than C patients. Regarding liver disease severity, chronic hepatitis B compared with chronic hepatitis C patients had significantly lower white blood cell and platelet counts, but similar biochemical (aminotransferases levels) and histological (grading and staging) findings as well as a similar prevalence of all other thrombophilic or coagulation factors (tables 1, 3).

In conclusion, our data suggest that thrombotic risk factors are frequently detected in patients with chronic viral hepatitis and that the presence of at least one of the significant factors (antithrombin III, protein C, or plasminogen deficiency, and activated protein $\mathrm{C}$ resistance) is associated with more extensive fibrosis and advanced staging. Whether the association of such thrombophilic conditions with advanced staging of chronic viral hepatitis is a primary or secondary phenomenon and whether their development in combination with local inflammation accelerate the progression of liver fibrosis need further evaluation. 
Authors' affiliations

G V Papatheodoridis, E Papakonstantinou, E Andrioti, E Cholongitas, K Petraki, I Kontopoulou, S J Hadziyannis, Hippokration General Hospital, Athens, Greece

\section{REFERENCES}

1 Tong MJ, El-Farra NS, Reikes AR, et al. Clinical outcomes of transfusion-associated hepatitis. N Engl J Med 1995;332:1463-6.

2 Poynard T, Bedossa P, Opolon P. Natural history of liver fibrosis progression in patients with chronic hepatitis $\mathrm{C}$. Lancet 1997;349:825-32.

3 Liaw YF, Tai DI, Chu CM, et al. The development of cirrhosis in patients with chronic type B hepatitis: a prospective study. Hepatology 1988:8:493-6.

4 Fattovich G, Brollo L, Giustina G, et al. Natural-history and prognostic factors for chronic hepatitis type B. Gut 1991;32:294-8.

5 Niederau C, Lange S, Heintges T, et al. Prognosis of chronic hepatitis C: results of a large, prospective cohort study. Hepatology 1998:28:1687-95.

6 Fattovich G, Giustina G, Degos F, et al. Morbidity and mortality in compensated cirrhosis type C: a retrospective follow-up study of 384 patients. Gastroenterology 1997; 1 12:463-72.

7 Weissberg JI, Andres LL, Smith Cl, et al. Survival in chronic hepatitis B. Ann Intern Med 1984;101:613-16.

8 de Jongh FE, Janssen HLA, de Man RA, et al. Survival and prognostic indicators in $\mathrm{HBs} A g$-positive cirrhosis of the liver. Gastroenterology 1992:103:1630-5.

9 Sherlock S. Hepatic cirrhosis. In: Sherlock S, ed. Diseases of the liver and biliary system. Oxford: Blackwell Scientific Publications, 1989:410-24.

10 Desmet VJ, Gerber M, Hoofnagle JH, et al. Classification of chronic hepatitis: diagnosis, grading and staging. Hepatology 1994:19:1513-120.

11 Ishak K, Baptista A, Bianchi L, et al. Histological grading and staging of chronic hepatitis. J Hepatol 1995;22:696-9.

12 The French METAVIR Cooperative Study Group. Intraobserver and interobserver variations in liver biopsy interpretation in patients with chronic hepatitis C. Hepatology 1994;20:15-20.
13 Karvountzis GG, Redeker AG, Peters RL. Long-term follow-up studies of patients surviving fulminant viral hepatitis. Gastroenterology 1974:67:870-7.

14 Wanless IR, Wong F, Blendis LM, et al. Hepatic and portal vein thrombosis in cirrhosis: possible role in development of parenchymal extinction and portal hypertension. Hepatology 1995;21:1238-47.

15 Wanless IR, Liu JJ, Butany J. Role of thrombosis in the pathogenesis of congestive hepatic fibrosis (cardiac cirrhosis). Hepatology $1995 \cdot 21: 1232-7$

16 Papatheodoridis GV, Burroughs AK. Hemostasis in hepatic and biliary disorders. In: LH Blumgart, Fong Y, eds. Surgery of the liver and biliary tract. London: WB Saunders, 2000:199-213.

17 Goodman ZD, Ishak KG. Occlusive venous lesions in alcoholic liver disease: a study of 200 cases. Gastroenterology 1982:83:786-96.

18 Nakanuma Y Ohta G, Doishita K. Quantitation and serial section observations of focal veno-occlusive lesions of hepatic veins in liver cirrhosis. Virchows Arch (Pathol Anat) 1985;405:429-38.

19 Friedman SL. The cellular basis of hepatic fibrosis: mechanisms and treatment strategies. N Engl J Med 1993;328:1828-35.

20 Brenner DA, Waterboer T, Choi SK, et al. New aspects of hepatic fibrosis. J Hepatol 2000;32 (suppl 1):32-8.

21 Green AF, Rantoff OD. Elevated antihaemophilic factor (AHF, factor VIII) procoagulant activity and AHF-like antigen in alcoholic cirrhosis of the liver. J Lab Clin Med 1974;83:189-97.

22 Clouse LH, Comp PC. The regulation of hemostasis: The protein C system. N Engl J Med 1986;314:1298-304.

23 Rosendaal FR. Venous thrombosis: a multicausal disease. Lancet 1999:353:1167-73.

24 Uthman IW Gharavi AE. Viral infections and antiphospholipid antibodies. Semin Arthritis Rheum 2002;31:256-63.

25 Prieto J, Yuste JR, Beloqui O, et al. Anticardiolipin antibodies in chronic hepatitis $C$ : implication of hepatitis $C$ virus as the cause of the antiphospholipid syndrome. Hepatology 1996;23:199-204.

26 Malnick SD, Abend Y, Evron E, et al. HCV hepatitis associated with anticardiolipin antibody and a cerebrovascular accident. J Clin Gastroenterol 1997:24:40-2.

27 Ordi-Ros J, Villarreal J, Monegal F, et al. Anticardiolipin antibodies in patients with chronic hepatitis $C$ virus infection: characterization in relation to antiphospholipid syndrome. Clin Diagn Lab Immunol 2000;7:241-4. 